\title{
AODV ROUTING PROTOCOL IMPLEMENTATION IN VANET
}

\author{
Dr. Ajay N. Upadhyaya \\ Computer Engineering Department, \\ Ahmedabad Institute of Technology, Ahmedabad, India \\ Dr. J.S. Shah \\ Computer Engineering Department, \\ Ex. Principal, Government Engineering College, Patan, India
}

\begin{abstract}
VANET is a scalable and unbounded network which is completely independent from the number of nodes. In VANET, communication is done between V2V (Vehicle to Vehicle) and V2I (Vehicle to Infrastructure). In both type of communications nodes are gathering information from other nodes or from RSU which must be trustworthy. VANETs is having different security requirement for governing proper vehicular communication. VANET are specially design for nodes having high mobility with unbounded network structure and want to communicate time critical information in a secure way. There is a two category in routing protocol which involve in this communication: Proactive and Reactive. AODV is a demand based reactive routing protocol. AODV only establish the route when any need occurs. It is having route request-response mechanism through which it send the request for finding the route and based on received response it establish the optimal path. In this paper work of Reactive routing protocol AODV is presented with the implementation methods using different simulators like SUMO, MOVE and NS2. Here AODV implementation is presented with the details comparative result analysis using different parameters like Packet Drop Rate, Throughput, Average End to End Delay, Jitter and Network Routing Load.
\end{abstract}

Key words: VANET, AODV, SUMO, NS2, MOVE, Routing Attack.

Cite this Article: Dr. Ajay N. Upadhyaya and Dr. J.S. Shah, AODV Routing Protocol Implementation in VANET, International Journal of Advanced Research in Engineering and Technology, 10 (2), 2019, pp 585-595.

http://iaeme.com/Home/issue/IJARET?Volume=10\&Issue $=2$

\section{INTRODUCTION}

Work in the field of adhoc network is started since 1970. Initially it is known as packet radio networks. Mainly it is a concept of establishing temporary wireless network between moving nodes. MANET (Mobile Adhoc Network) and VANET (Vehicular Adhoc Network) gain the attraction due to their usability. VANET is an advancement over MANET which is following the movement of nodes based on road infrastructure. VANET communication can be categories 
in two categories: V2V (Vehicle to Vehicle) Communication and V2I (Vehicle to Infrastructure) Communication. A V2V communication is a communication between different vehicles having OBU (On Board Unit) devices. A V2I communication is a communication between OBU and RSU (Road Side Unit). This communication is carried out using different electromagnetic waves like infrared, microwaves and radio wave. In Implementation of VANET IEEE 802.11 standard is used. IEEE P1609.1 is the standard for WAVE (Wireless Access in Vehicular Environment) based on DSRC (Dedicated Short Range Communication). WAVE uses a IEEE 802.11a with some modification which is known as IEEE 802.11p. In 2003 established the service and license rules for DSRC services, which uses the 5.850 to $5.925 \mathrm{GHz}$ bandwidth $(75 \mathrm{MHz})$ for the use of public safety and private applications. Routing is a main process of network layer through which it transmits the packet using optimal path. Routing process is a responsibility of routing protocols. Routing is categories in main two categories: Reactive and Proactive routing. Here we will present the implementation and analysis of AODV - A most vulnerable routing protocol.

\section{SIMULATION METHODOLOGY}

Here three different Simulator tools have taken for analysing the behaviour of AODV in VANET: SUMO, MOVE and NS2. For explaining the flow of work in simple way work is presented using a simple cross road implementation and same flow is used for designing different scenario.

\subsection{SUMO}

SUMO (Simulation of Urban MObility) is a simulator for vehicular adhoc network for designing and analysing [01-06] the different mobility patterns of vehicles.

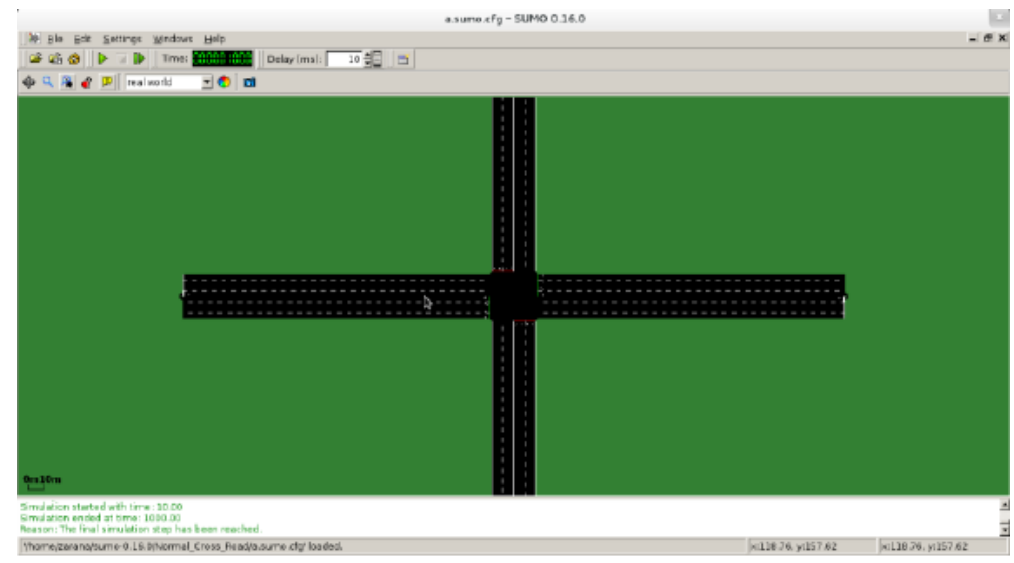

Figure 1 Cross Road Implementation in SUMO 0.16.0

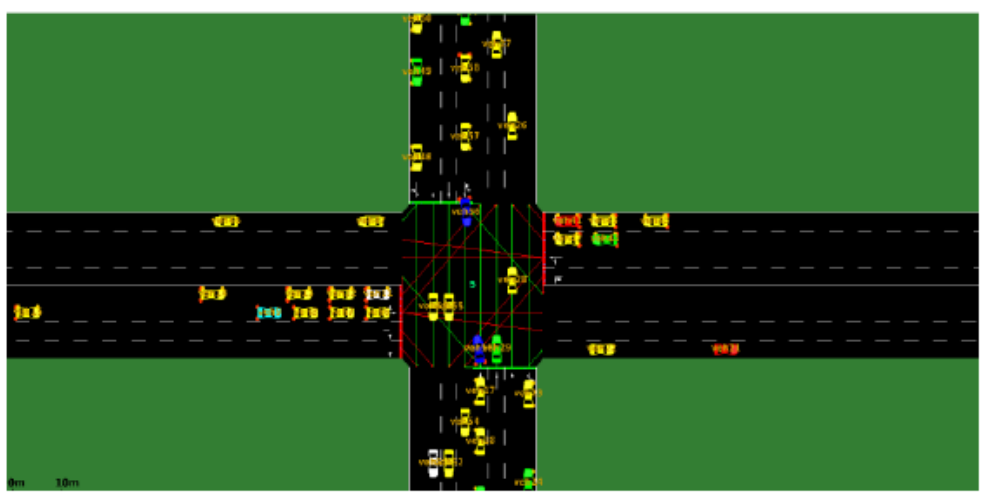

Figure 2 Cross Road Implementation in SUMO 0.16.0 
Figure-1 is presenting simple single cross road implementation in SUMO with Traffic Light. Figure-2 is presenting cross road implementation with different types of vehicle deployment.

Figure-3 is presenting City Scenario with multiple cross road and $\mathrm{T}$ junction with heterogeneous environment of road and vehicle using OSM (Open Street Map) map. We loaded Ahmedabad OSM map for designing real time scenario.

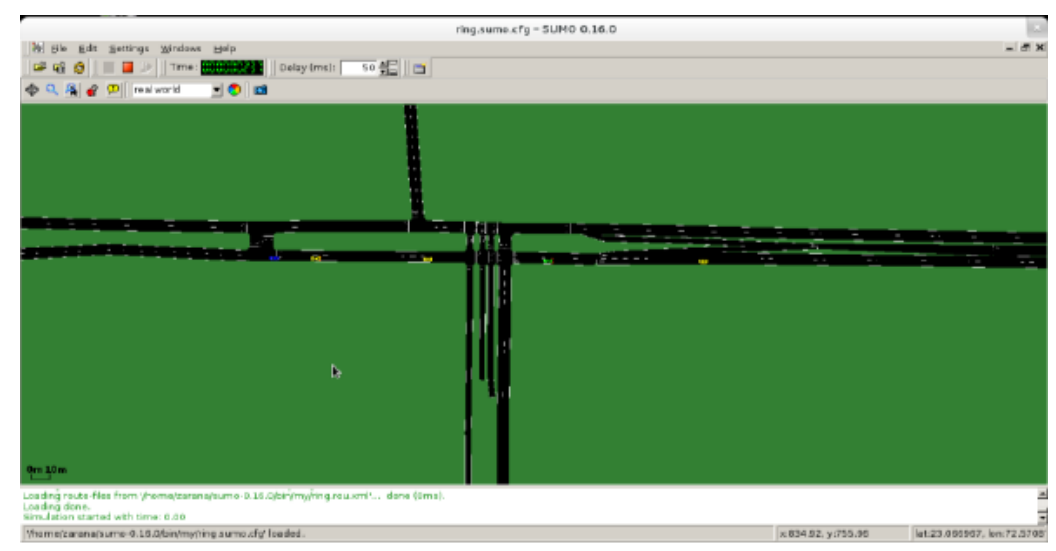

Figure 3 City Scenario in SUMO 0.16.0

For scenario generation we will follow the following steps in SUMO 0.16.0.

Step 1: Manually create your own map nodes (a.nod.xml)

Step 2: Manually create your own map edge (a.edg.xml)

Step 3: Create map configuration file (a.netc.cfg).

Step 4: Generate the Map file (a.net.xml)

Step 5: Using Flow definition (a.flow.xml)

Step 6: Automatic vehicle movements (a.rou.xml)

Step 7: Simulation setup (a. sumo.tr and a.sumo.cfg)

Step 8: Visualize Simulation

Step 9: Generating Trace files using trace Exporter utility but it is more feasible to generate it using MOVE.

\subsection{MOVE}

MOVE (MObility model generator for VEhicular networks) is a simulator through which Trace file can be generated. It required back end support of SUMO [07-09]. A tool MOVE is used to facilitate users to rapidly generate realistic mobility models for VANET simulations. MOVE tool is built on top of an open source micro-traffic simulator SUMO. The output of MOVE is a mobility trace file which contains information of realistic vehicle movements. Output file of MOVE simulator can be directly used in other simulation tools such as ns- 2 or qualnet. 


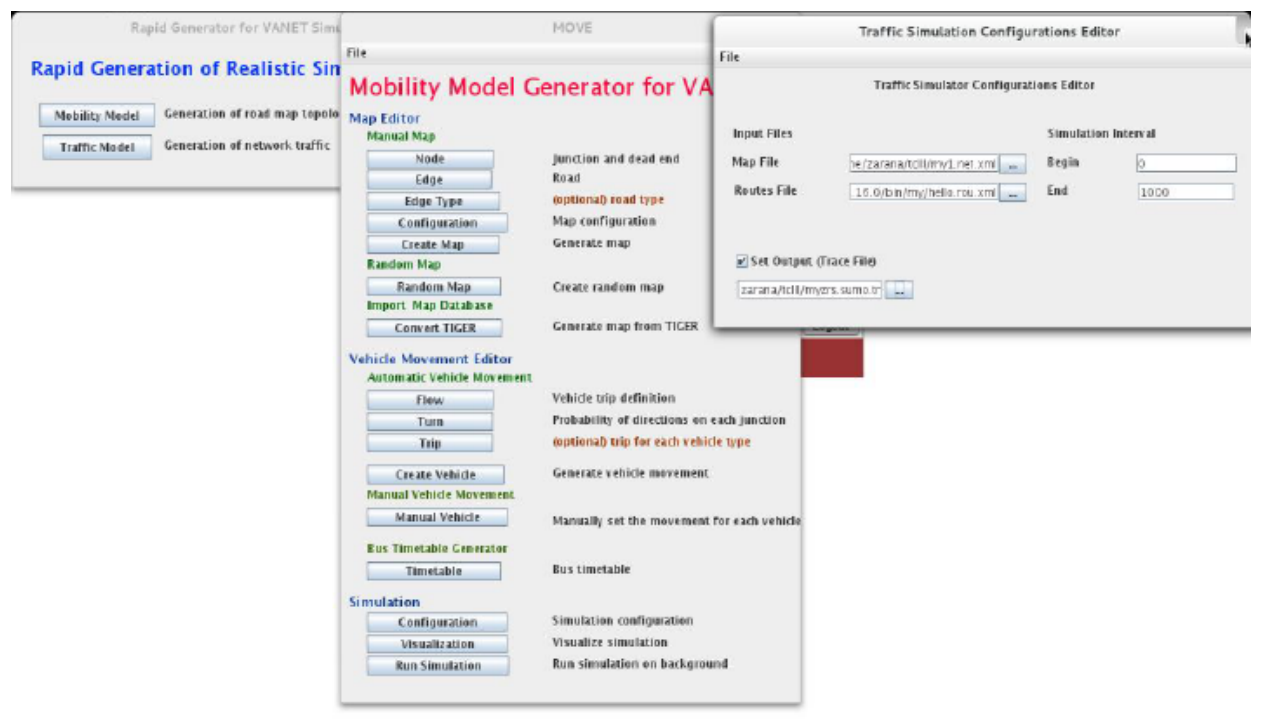

Figure 4 Generate trace File using Move

Main feature of MOVE is its graphical user interface support, which allows the user to quickly generate realistic simulation scenarios without the hassle of writing simulation scripts as well as learning about the internal details of the simulator. Figure-4 is presenting the trace file generation and Figure-5 is presenting TCL file generation in MOVE. TCL File can be generated from Traffic Model part of MOVE. Figure-6 is presenting nam file generation in MOVE. Run TCL into NS2 in Background Console using MOVE and it will generate nam and .tr files.

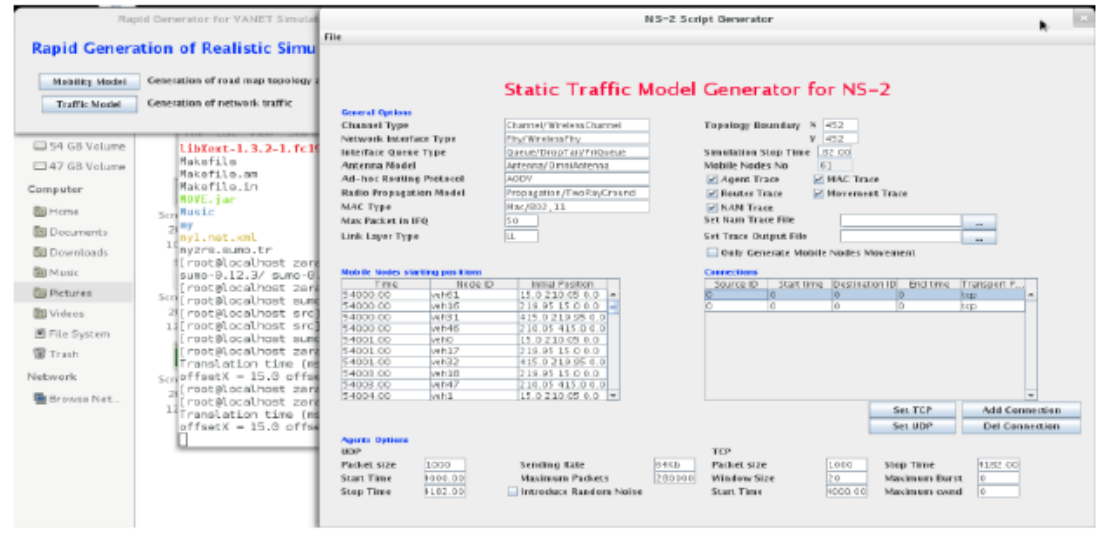

Figure 5 Generate TCL File using Move

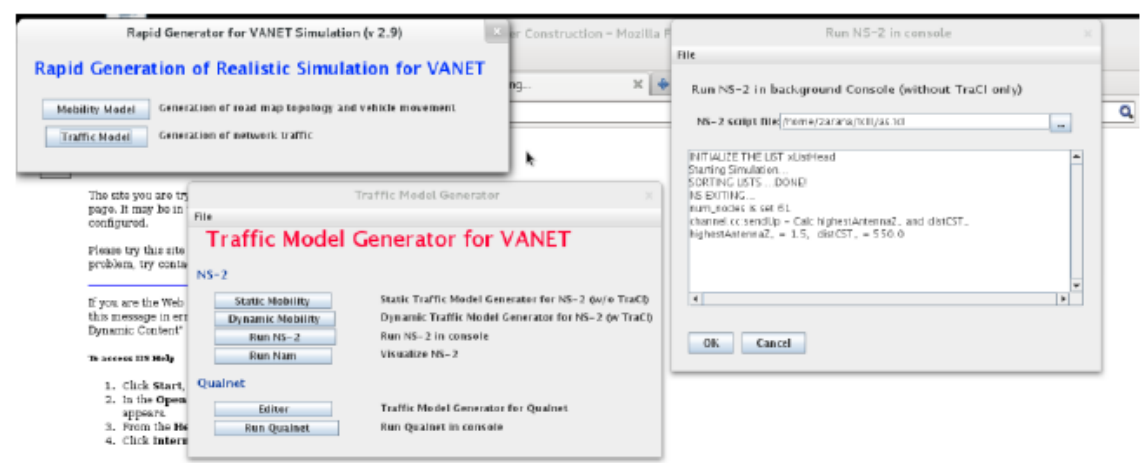

Figure 6 Generate NAM File using Move 


\subsection{NS2}

NS-2 is an open-source discrete event network simulator that supports both wired and wireless networks. Generally mainly it is use for MANET and VANET routing protocols and an implementation. NS-2 simulates the physical layer and the important parameters that influence its behavior. Nam editor can be used to run .nam file into NS2 [10-14]. NS2 is a Network Simulator Tool which is open source. Here NS2.34 is used for simulating network. Figure-7 is presenting running nam editor in NS2. Figure-8,9 and 10 presenting visualization of cross road in NS2 which was created in SUMO.

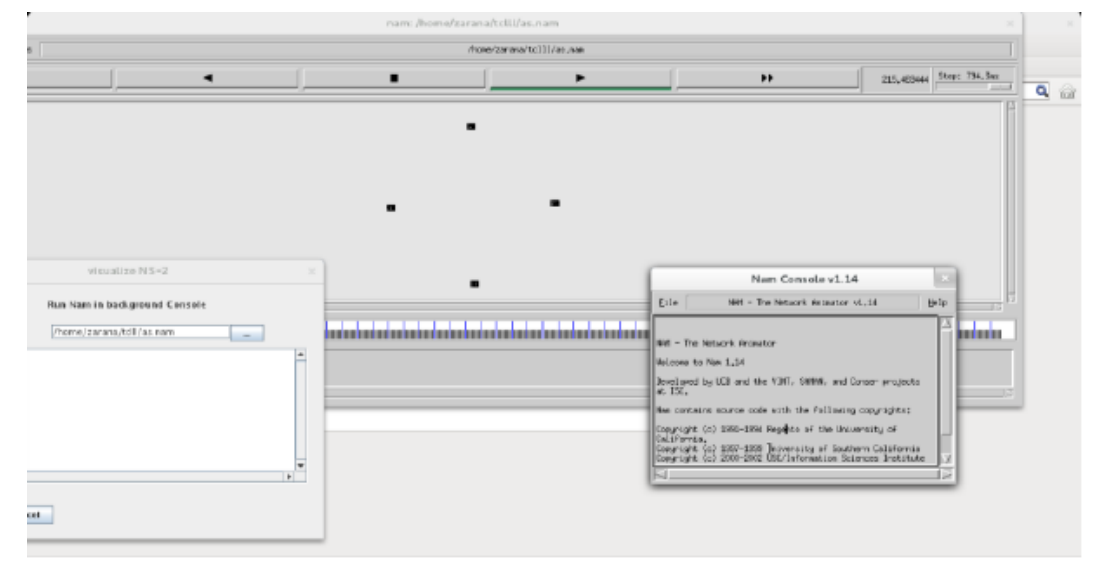

Figure 7 Run .nam file in Nam editor in NS2

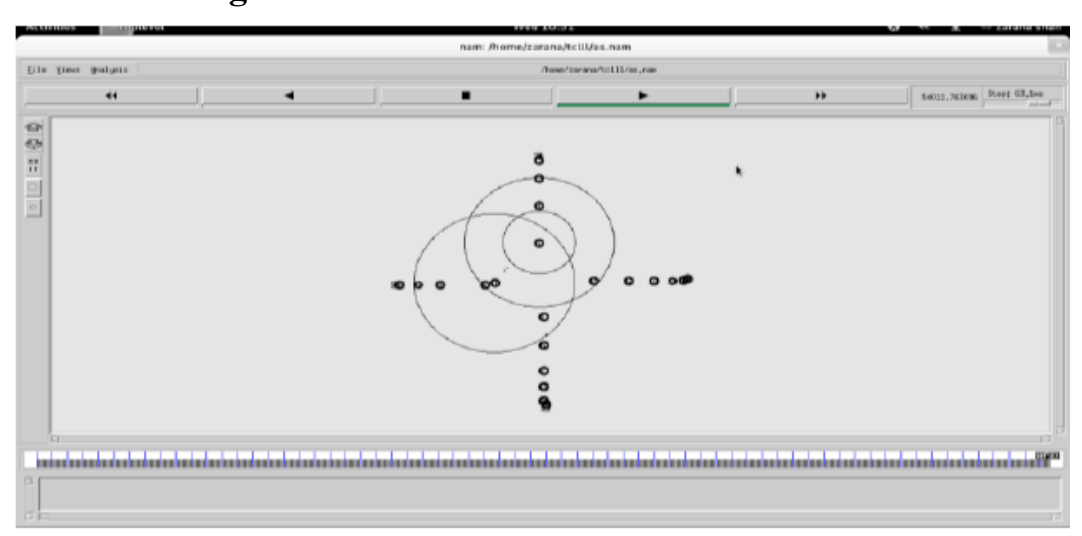

Figure 8 Visualise Simulation in NS2 of Cross Road created in SUMO 0.16.0 stage-1

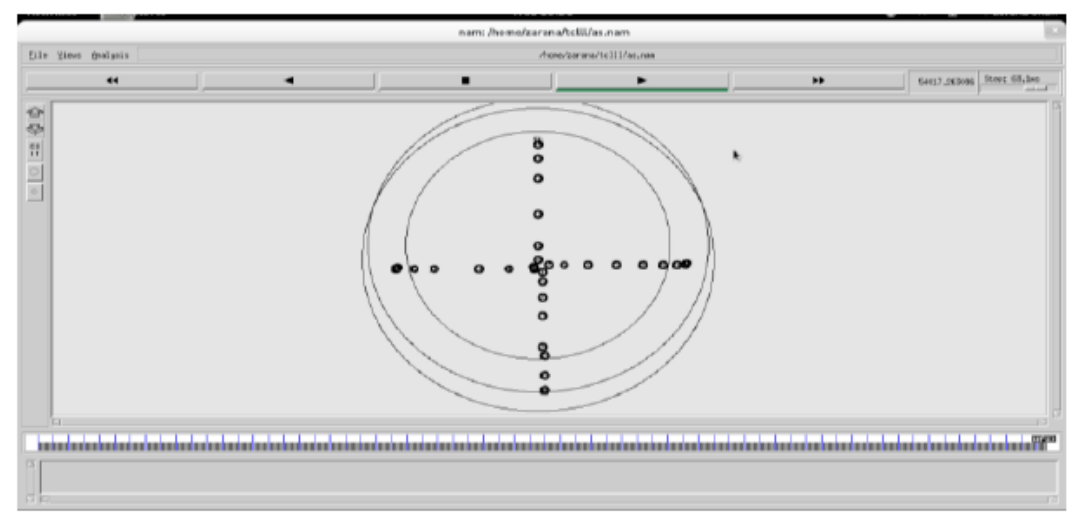

Figure 9 Visualise Simulation in NS2 of Cross Road created in SUMO 0.16.0 stage-2 


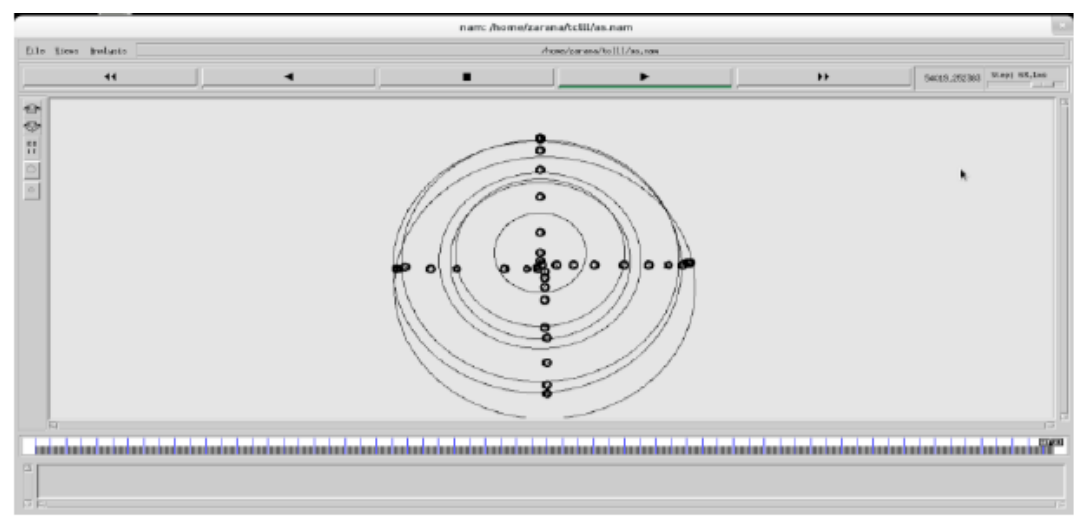

Figure 10 Visualise Simulation in NS2 of Cross Road created in SUMO 0.16.0 stage-3

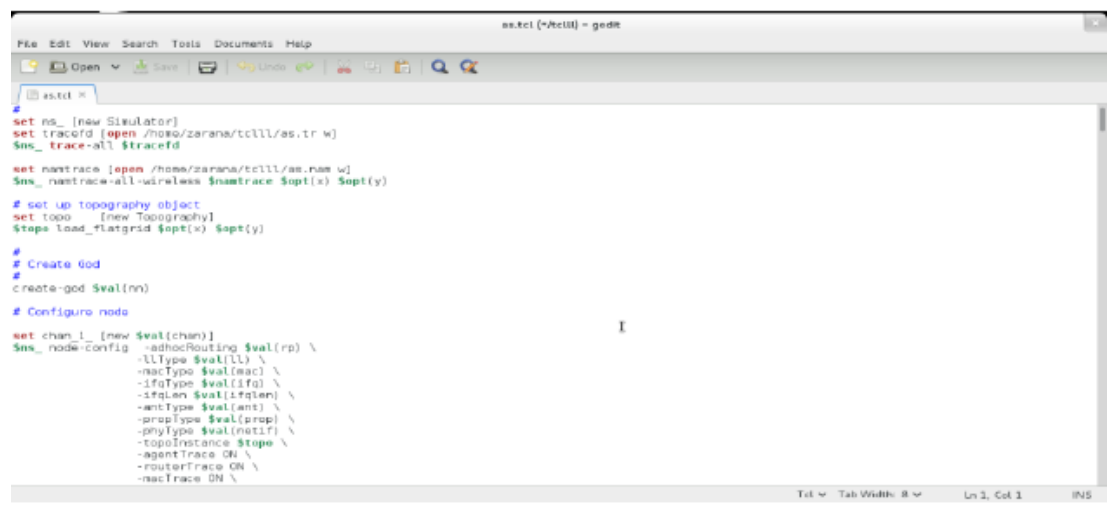

Figure 11 TCL file (as.tcl)

Figure-11 is presenting the content of TCL File and Figure-12 is presenting the content of nam file. Here AODV Routing Protocol is used. After the successfully execution trace file is generated as shown in Figure-13 which is useful to generate different result. AWK script can be used to generate different type of Result.

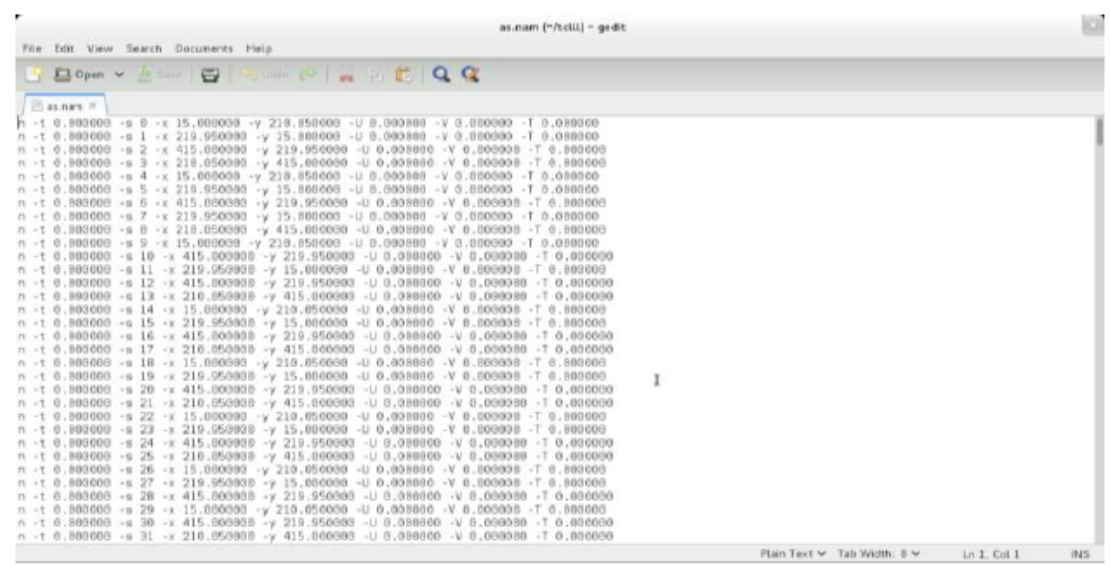

Figure 12 TCL file (as.nam) 


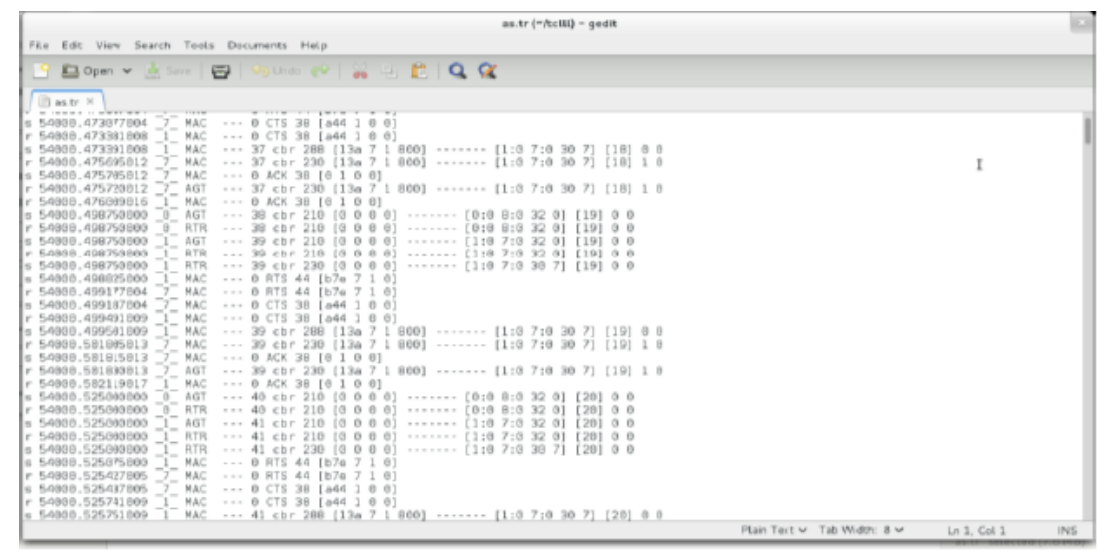

Figure 13 Trace file (as.tr)

\section{PERFORMANCE METRICS}

Figure-11 is presenting the content of TCL File and Figure-12 is presenting the content of nam file. Here AODV Routing Protocol is used. After the successfully execution trace file is generated as shown in Figure-13 which is useful to generate different result. AWK script can be used to generate different type of Result.

\subsection{Packet Drop Rate (PDR)}

Packet Drop Rate defines the total number of packets drop packets over total number of transmitted packet. by all nodes in the network. It is defined as

Packet Drop Rate $\left(\right.$ PDR) $=\frac{\text { Total No. Packets Sent }- \text { Total No. of Packets Received }}{\text { Total No. of Packet Sent }}$

Here Packet Delivery Ratio can be calculated by

Which is a same as,

$$
\text { Packet Delivery Ratio }=\frac{\text { Total No. of Packets Received }}{\text { Total No. of Packet Sent }}
$$

Packet Delivery Ratio $=100-$ Packet Drop Rate $($ PDR)

\subsection{Average End-to-End Delay}

This parameter is based on total average transmission time of each packet from source to destination. This traversal time is known as Average End to End Delay(E2E Delay). It is defined as

$$
\text { Avg. E2E Delay }=\frac{\sum_{i=0}^{n}[\text { End Time }(\mathrm{t} 2)-\text { Start Time }(\mathrm{t} 1)]}{\text { Total No. of Packets }}
$$

\subsection{Network Throughput}

This parameter defines the success rate of message transmission over a particular communication medium. Network Throughput gives details about actual data rate of network through which capacity of network can be identified.

$$
\text { Throughput }(\mathrm{Th})=\frac{\text { Total Data Sent }(\mathrm{Kb})}{\text { Total Time }(\mathrm{S})}
$$




\subsection{Jitter}

Average Jitter is the variation in the delay introduced by the vehicle components along the communication path in VANET. It is the variation in the total time between arriving of packets. Jitter is used to specify consistency ans stability of network. The delays variation between the different packets need to be low for getting best performance in VANETs.

$$
\text { Avg. Jitter }=\frac{\sum_{i=0}^{n}[|\mathrm{D}(\mathrm{i}+1)-\mathrm{D}(\mathrm{i})|]}{\text { Total No. of Packets }}, \text { Where } \mathrm{Di}=\mathrm{R}(\text { time })-\mathrm{S}(\text { time })
$$

\subsection{Normalized routing load (NRL)}

Every protocol is adding routing information for managing packet transmission smoothly. The addition of this packets is considered as an extra load or Routing Overhead for data packet transmission which specifies the stress level added by particular protocol. It is defined as

$$
\text { Normalized routing load }(\mathrm{NRL})=\frac{\text { No. of Routing Packet Sent }}{\text { No. of Data Packet Sent }}
$$

\section{ANALYSIS OF AODV ROUTING PROTOCOL IMPLEMENTATION}

Here city scenario is taken with different types of 500 vehicles. Ahmedabad OSM map is loaded in SUMO with the different vehicles. Simulation time 1000 seconds is taken. To generate the accurate result, run the same simulation five times with having the same parameters. Work is mainly focused on five different parameter: PDR (Packet Drop Rate), Th(Throughput), E2ED (Average End to End Delay), NRL (Network Routing Load) and Jitter as we discussed in section 3. Table I is presenting the simulation result for all five parameters.

\begin{tabular}{|c|c|c|c|c|c|c|}
\hline & Protocol $\rightarrow$ & & & AOD & & \\
\hline & $\begin{array}{c}\text { No. of } \\
\text { Nodes } \downarrow \\
\end{array}$ & $\begin{array}{l}\text { PDR } \\
(\%)\end{array}$ & $\begin{array}{c}\text { Th } \\
\text { (kbps) }\end{array}$ & $\begin{array}{c}\text { E2ED } \\
(\mathrm{ms})\end{array}$ & $\begin{array}{l}\text { Jitter } \\
\text { (ms) }\end{array}$ & $\begin{array}{c}\text { NRL } \\
(\%)\end{array}$ \\
\hline Observation-1 & \multirow{6}{*}{500} & 3.93 & 552.70 & 84.17 & 0.0445 & 6.1761 \\
\hline Observation-2 & & 3.96 & 545.84 & 89.11 & 0.0450 & 6.1780 \\
\hline Observation-3 & & 3.87 & 541.65 & 88.36 & 0.0454 & 6.1722 \\
\hline Observation-4 & & 3.82 & 550.49 & 87.04 & 0.0446 & 6.1690 \\
\hline Observation-5 & & 3.94 & 551.77 & 83.57 & 0.0445 & 6.1767 \\
\hline Average & & 3.90 & 548.49 & 86.45 & 0.0448 & 6.1744 \\
\hline
\end{tabular}

Table 1 Simulation Result for AODV Protocol

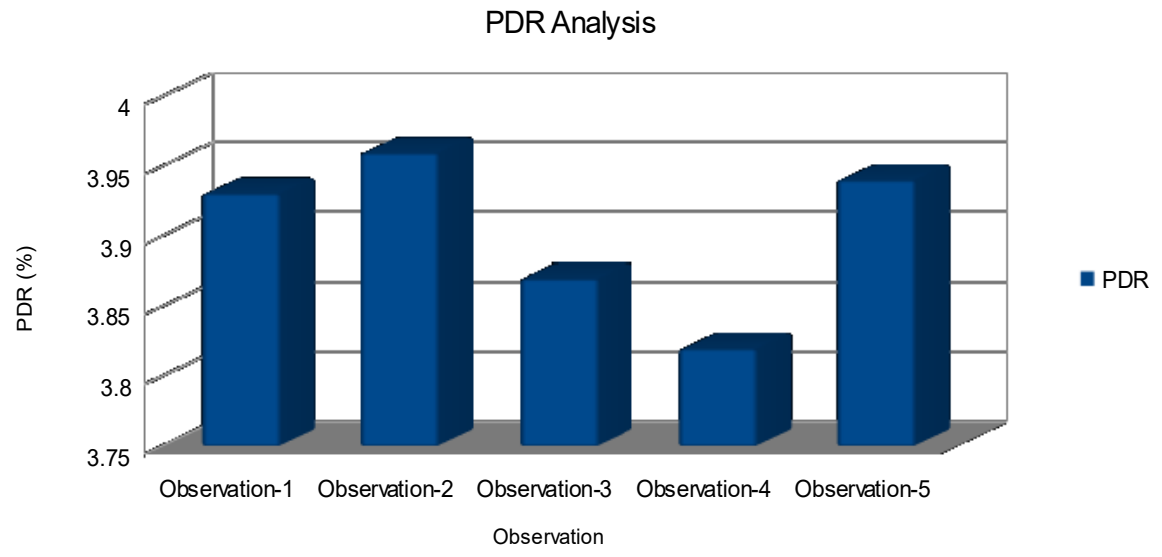

Figure 14 PDR Analysis 


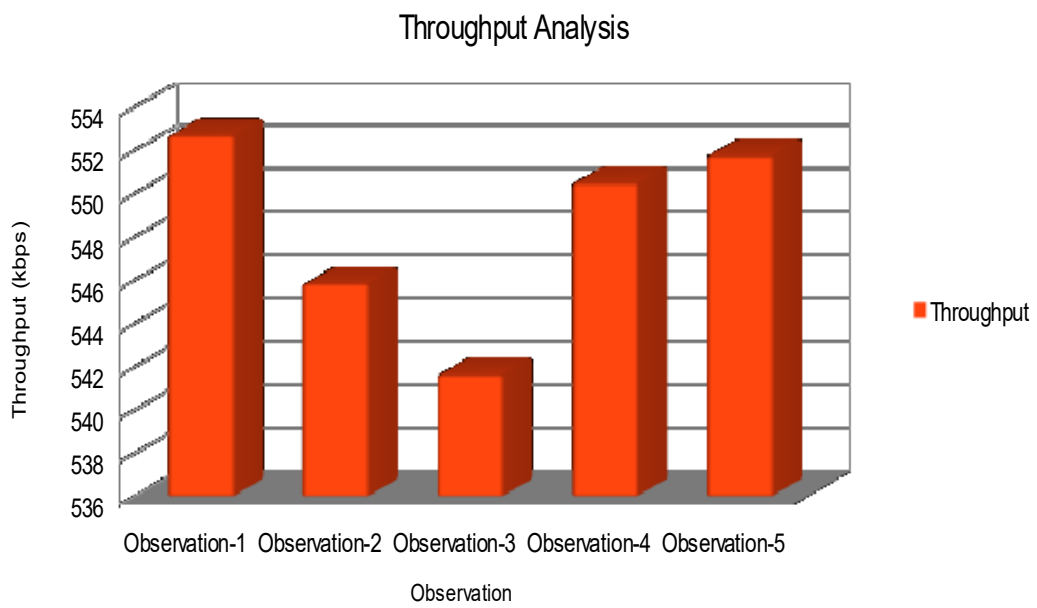

Figure 15 Throughput Analysis

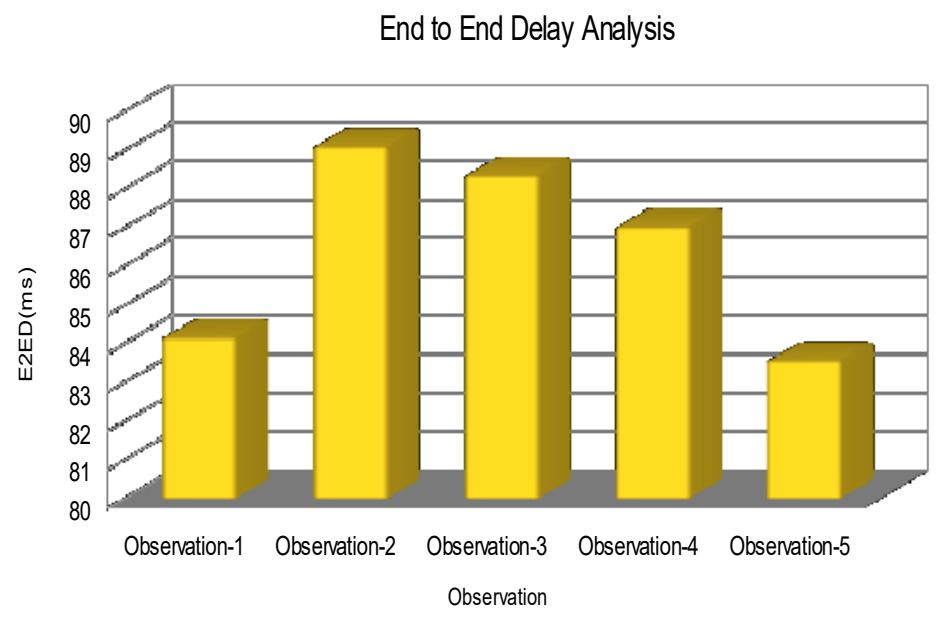

Figure 16 End to End Delay Analysis

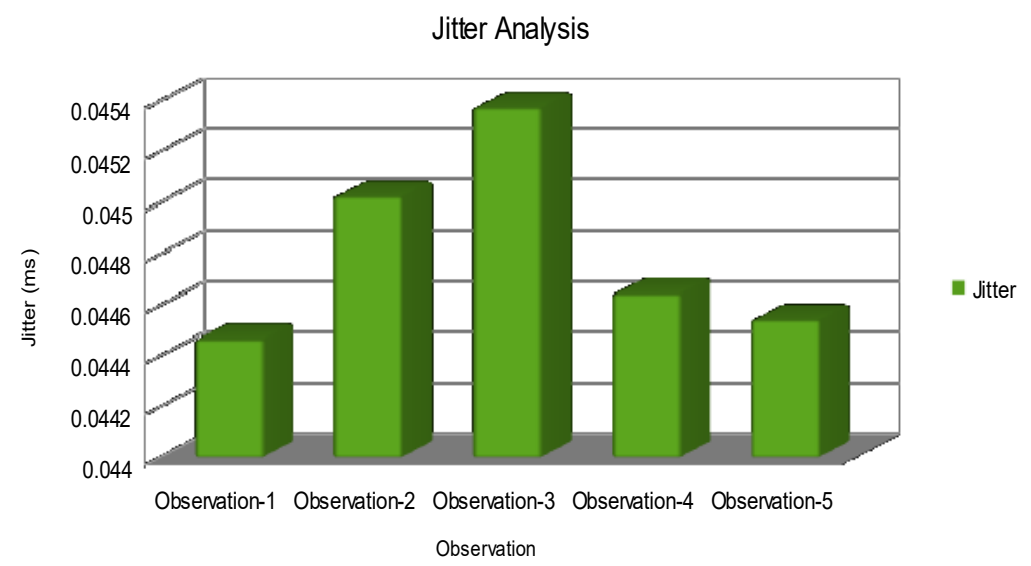

Figure 17 Jitter Analysis 


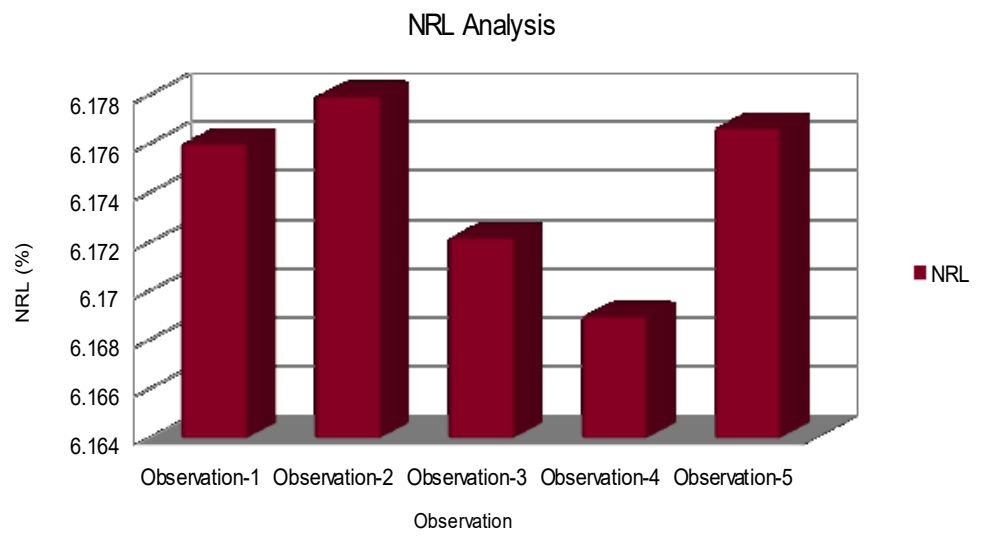

Figure 18 NRL Analysis

Figure 14 is presenting Packet Drop Rate Analysis, Figure 15 is presenting Throughput Analysis, Figure 16 is presenting Average End to End Delay Analysis, Figure 17 is presenting Jitter Analysis and Figure 18 is presenting Network Routing Load Analysis. Here comparative analysis is presented graphically for the different observation as per the table-I. Here we will consider the average value of each parameter for the further analysis.

\section{CONCLUSIONS}

We presented here implementation of AODV Routing protocol using the simulation tool SUMO, MOVE and NS2 and analyse the result using different parameters. Here we received Average PDR 3.90\%, Average Throughput $548.49 \mathrm{kbps}$, Average End to End Delay $86.45 \mathrm{~ms}$, Average Jitter $0.0448 \mathrm{~ms}$, Average Network Routing Load 6.1744 \%. AODV is most vulnerable protocol for the different routing attacks. By imposing such routing attack in network we can easily measure the effect on different parameters. In future we will work on heterogeneous traffic with different number of vehicles and also check security loopholes in VANET Network with AODV Protocol.

\section{REFERENCES}

[1] K. G. Lim, C. H. Lee, R. K. Y. Chin, K. Beng Yeo and K. T. K. Teo, "SUMO enhancement for vehicular ad hoc network (VANET) simulation," 2017 IEEE 2nd International Conference on Automatic Control and Intelligent Systems (I2CACIS), Kota Kinabalu, 2017, pp. 86-91.

[2] A. Srivastava, G. Kapoor and A. Gupta, "Solving traffic congestion - An application of VANET," 2016 International Conference on Innovation and Challenges in Cyber Security (ICICCS-INBUSH), Noida, 2016, pp. 323-326.

[3] Prerna Malhotra, A Survey of Energy Efficient Aodv Routing Algorithms in Manet, International Journal of Computer Engineering and Technology (IJCET), Volume 4, Issue 2, March - April (2013), pp. 213-220

[4] V. Kolici, T. Oda, Y. Sugihara, E. Spaho, M. Ikeda and L. Barolli, "Performance Evaluation of a VANET Simulation System Using NS-3 and SUMO Considering Number of Vehicles and Crossroad Scenario," 2015 9th International Conference on Innovative Mobile and Internet Services in Ubiquitous Computing, Blumenau, 2015, pp. 22-27.

[5] A. K. Ali, I. Phillips and H. Yang, "Evaluating VANET routing in urban environments," 2016 39th International Conference on Telecommunications and Signal Processing (TSP), Vienna, 2016, pp. 60-63.

[6] Vijay Singh Chongad and Dhiraj Nitnaware, Energy Based AODV Routing Protocol for Wireless Mesh Network. International Journal of Advanced Research in Engineering and Technology, 9(4), 2018, pp 77-83. 
[7] B. Hamid and E. E. Mokhtar, "Performance analysis of the Vehicular Ad hoc Networks (VANET) routing protocols AODV, DSDV and OLSR," 2015 5th International Conference on Information \& Communication Technology and Accessibility (ICTA), Marrakech, 2015, pp. 16.

[8] SUMO Simulation of Urban Mobility. http://sumo.sourceforge.net/.

[9] Miss. P.A. Kamble and Dr. M.M. Kshirsagar, Improvement Over Aodv Routing Protocol in Vanet, International Journal of Computer Engineering and Technology (IJCET), Volume 4, Issue 4, July-August (2013), pp. 315-320

[10] T. Mantoro and M. Reza, "Performance analysis of AODV and DSDV using SUMO, MOVE and NS2," 2016 International Conference on Informatics and Computing (ICIC), Mataram, 2016, pp. 372-376.

[11] F. K. Karnadi, Z. H. Mo and K. Lan, "Rapid Generation of Realistic Mobility Models for VANET," 2007 IEEE Wireless Communications and Networking Conference, Kowloon, 2007, pp. 2506-2511.

[12] MOVE http://www.cs.unsw.edu.au/klan/move

[13] B. Goswami and S. Asadollahi, "Novel approach to improvise congestion control over vehicular ad hoc networks (VANET)," 2016 3rd International Conference on Computing for Sustainable Global Development (INDIACom), New Delhi, 2016, pp. 3567-3571.

[14] Muthaiah R, Kavitha T, Review on Adaptations to AODV Routing Protocol to Mitigate Blackhole Attacks in Mobile Ad hoc Networks, International Journal of Mechanical Engineering and Technology, 8(8), 2017, pp. 406-410.

[15] O. Salman, R. Morcel, O. Al Zoubi, I. Elhajj, A. Kayssi and A. Chehab, "Analysis of topologybased routing protocols for VANETs in different environments," 2016 IEEE International Multidisciplinary Conference on Engineering Technology (IMCET), Beirut, 2016, pp. 27-31.

[16] S. Chettibi, Y. Labeni and A. Boulkour, "Trace file analyzer for ad hoc routing protocols simulation with NS2," 2015 First International Conference on New Technologies of Information and Communication (NTIC), Mila, 2015, pp. 1-6.

[17] Jayashree Agarkhed, Study of Security Enhancement in AODV Routing Protocol in Ad hoc Networks. International Journal of Computer Engineering \& Technology, 8(5), 2017, pp. 99106

[18] M. Singh and J. Sharma, "Performance analysis of secure \&amp; efficient AODV (SE-AODV) with AODV routing protocol using NS2," Proceedings of 3rd International Conference on Reliability, Infocom Technologies and Optimization, Noida, 2014, pp. 1-6.

[19] The Network Simulator ns 2. http://www.isi.edu/nsnam/ns/index.html. 